\title{
Emotion Regulation and the Dynamics of Feelings: A Conceptual and Methodological Framework
}

\author{
Jan B. Hoeksma, Jaap Oosterlaan, and Eline M. Schipper
}

\begin{abstract}
The emotional system is defined as a dynamical system that has neurological and biochemical structures that force the system to change in a regular and consistent way. This dynamic view allows for an alternative definition of emotion regulation, which describes when emotion regulation is needed, identifies its goal, and illustrates how regulation is achieved. The thesis developed here is that feelings - the private mental experience of emotion - play a crucial role in emotion regulation. Specifics of regulation are discussed and a parallel with parent-child interaction is drawn. It is shown that emotion regulation can be studied by looking at the variability of feelings. An illustrative application $(N=30$, age 10-13 years) shows that variability of anger is associated with the core executive function response inhibition.
\end{abstract}

The emotion researcher Claus Scherer recently argued for a radical departure from the classic paradigm of emotion psychology. He proposed to shift emphasis from emotions as states to emotions as processes, that is, to the constantly changing affective tuning of the organism. Although many theorists have endorsed the notion of emotions as dynamic processes, "most research has been firmly wedded to the notion of emotional state" (Scherer, 2000, p. 70).

Cole, Martin, and Dennis (this issue), focusing on emotion regulation, came to a remarkably similar conclusion. They stressed that emotion regulation can be inferred only from change. However, few studies have been designed to do so. Cole et al. challenged researchers to devise theories and methods that incorporate change and that make a clear distinction between emotion and emotion regulation. In this article we take up that challenge. We combine recent insights from emotion theories about the dynamic nature of the emotional system (Damasio, 1994; Frijda \& Zeelenberg, 2001; Lewis, 1996; Scherer, 1987, 2001; Schore, 2000) with findings from (mathematical) signal and system theory (Box, Jenkins, \& Reinsel, 1994; Goodwin \& Sin, 1984; Grewal \& Andrews, 1993). Dynamic emotion theories are about change by definition, whereas concepts from signal

Jan B. Hoeksma and Eline M. Schipper, Developmental Psychology, Vrije Universiteit. Jaap Oosterlaan, Clinical Neuropsychology, Vrije Universiteit.

The authors wish to thank Hans Koot for his comments on an earlier version of this paper and René Nieuwboer for preparing the stop signal task.

Correspondence concerning this article should be addressed to Jan B. Hoeksma, Vrije Universiteit, Developmental Psychology, Van der Boechorststraat 1, 1081 BT Amsterdam, The Netherlands. Electronic mail may be sent to jb.hoeksma@psy.vu.nl and system theory help clarify the difference between emotion and emotion regulation.

In this contribution, we propose a three-component definition that makes a clear distinction between emotion and emotion regulation. This definition leads to a focus on the change and variability of feelings in the study of the emotion-regulation process and the factors affecting this process.

\section{Emotional System}

The emotional system is an interconnected network of neurological structures including the thalamus, hypothalamus, hippocampal formation, amygdala, cingulate cortex, and prefrontal cortex (Davidson \& Irwin, 1999; Kolb \& Whishaw, 2003). Most of these structures project to each other reciprocally, resulting in positive and negative feedback loops (Freeman, 2000). These feedback loops create emotional circuits that allow for continuous changes of the state of the system. Changes in the emotional system are further modulated by a set of neuromodulators including acetylcholine, serotonin, and others that follow their own time cycles (Hobson, 2001; Panksepp, 1998). The neurological and biochemical structures impose constraints that force the emotional system to change in regular and consistent way inherent to the system.

Because the state of the system changes continuously, the emotional system is called dynamic. The emotional process is the evolution of the emotional system in time. The emotional system has a biologically based regulatory role (Ekman, 1972; Frijda, 1986; Plutchik, 1962) and works continuously, night and day (Hobson, 2001; Maquet et al., 1996;

(C) 2004 by the Society for Research in Child Development, Inc. All rights reserved. 0009-3920/2004/7502-0006 
Scherer, 2001). It is inherent in the process of promoting and maintaining life, and is always poised to prevent the loss of physical and psychological integrity (Damasio, 2000b). Increased activity of the emotional system is induced by representations of objects and situations (appraisals) that threaten or facilitate a person's goals and concerns (Frijda, 1986). These representations may originate from outside or inside the person (e.g., conjured from memory or construed through imagination), or they may directly reflect the internal milieu (Damasio, 2000b).

Emotions are not the same as feelings (Scherer, 2000). The term feeling refers to the private mental experience of emotions (Damasio, 2000b). More than a century after James (1884), it is still not fully clear how feelings are produced (Cacioppo, Berntson, Larsen, Poehlmann, \& Ito, 2000; Heilman, 2000). Nevertheless, there is growing agreement on the crucial importance of feelings (Solomon, 2002). Consistent with others' views (e.g., Damasio, 2000a; Greenfield, 2000; Panksepp, 1998; Scherer, 2000) we assume that feelings monitor changes in the ongoing emotional system. They inform the higher cognitive processes of the changing state of the emotional system and affect these cognitive processes accordingly (Damasio, 2000a; Panksepp, 1998). Feelings are not mere epiphenomena of the activity of the emotion system but instead play a causal role by affecting its state (Panksepp, 1998) and offer survival value (Damasio, 2000a; Greenfield, 2000).

\section{Emotion Regulation}

Our view of the emotional system as a dynamic system is simple but largely compatible with the far more detailed theorizing on dynamical aspects of the emotional system by Damasio (1994, 2000a, 2000b), Frijda \& Zeelenberg (2001), Scherer (2000), and Lewis (1996). Understanding the emotional system as a dynamic system allows us to use concepts and ideas from signal and system theory. Signal and system theory (a branch of general systems theory) is a mathematical theory concerned with the design and construction of dynamic systems (Box et al., 1994; Goodwin \& Sin, 1984; Grewal \& Andrews, 1993). It has been applied to numerous problems in engineering, ranging from filtering and controlling radio sounds, to planning oil refineries, to guiding unmanned rockets to the moon.

Key concepts from signal and system theory are feedback, prediction, and control (Box et al., 1994). The concept of control may be especially useful for understanding the concept of emotion regulation. Whereas the distinction between emotion and emo- tion regulation often appears problematic (Cole et al., this issue), the distinction between the physical dynamic system and controlling the system is always clear. To illustrate, a spacecraft on its way to the moon is seen as a dynamic system. The power of its engines is seen as input. The place and velocity of the spacecraft describe its state. Changing the spacecraft's velocity is control. From an engineering perspective, the concept of control has three components (cf. Kamen \& Heck, 1997): (a) control is needed when the state of the system is expected to diverge from a reference signal or set point (e.g., when the velocity is going to exceed some limit), (b) the goal of control is to force the state of the system into a preferred direction (e.g., turning down its speed), and (c) this change of state in a preferred direction is achieved by changing the input of the system (e.g., turning down the engines).

These three components derived from signal and control theory allow us to define emotion regulation. We use an example to clarify the definition. Our protagonist is a 9-year-old oppositional schoolboy. He feels insulted by his schoolteacher. He is angry and on the verge of having a tantrum. But then his eyes and his teacher's eyes meet each other. Our protagonist must take care. Analogous to control, the three defining components of emotion regulation might be described as follows:

1. Emotion regulation is needed when the expected state of the emotional system (feeling angry and possibly acting angry in the presence of an authority figure) diverges from the set goal of the emotional system, that is, maintaining the child's physical and psychological integrity (anger directed at an authority figure might lead to physical or psychological punishment).

2. The goal of emotion regulation is to force the state of the emotional system in a preferred direction in line with some reference signal or the set goal (in this case, preventing anger to run its full course, to keep quiet to save one's skin).

3. Change of the emotional state in the preferred direction is achieved by changing the input to the emotional system, for instance, by means of gaze aversion (turning his eyes away from the teacher), reappraisal of the situation ("It wasn't an insult really"; cf. Lazarus, 1991), or by changing the situation (e.g., leaving the classroom; cf. Gross, 1999).

Before addressing some specifics of emotion regulation and the role of feelings, we note that emotion 
regulation is no emotional thing. That is, representations of objects or situations that make emotion regulation relevant (e.g., the actual or imagined presence of the teacher), do not directly induce activity in the ongoing emotional system; that is, they do not produce emotions themselves. Instead, emotion regulation acts by altering the input of the ongoing emotional system. If emotion regulation is successful, the expected course (e.g., increasing anger) of the emotional system will be changed, and thus its state will be changed (e.g., decreasing anger). If emotion regulation is not successful, the system will continue its course (e.g., anger will increase to some maximum and then die out).

\section{Role of Feelings}

Emotion regulation is needed when the ongoing emotional system is derailed, that is, when the systems' expected emotional state is not in line with the individual's goals and concerns. We assume that the expected emotional state is inferred from current feelings. Feelings monitor the changing current emotional state of the dynamic emotional system. Because the autocorrelation of contiguous states (the current and expected state) in a regularly evolving dynamical system is strong (cf. Gottman, 1981), the current feelings also contain information on the expected emotional state. To illustrate, increasing anger (the current feeling) informs our protagonist that he is on the verge of a tantrum (the expected emotional state).

Current feelings inform the higher cognitive processes about the problem the emotional system has begun to solve (Damasio, 2000a). If the present feeling corresponding to the impeding emotional state does not fit the present circumstances, concerns, or long-term goals - that is, when the expected emotional state is a mismatch - the state of the emotional system must change. For example, the expected emotional state (anger at the teacher) is not appropriate for this circumstance (you will be sent to the principal's office if you scream at the teacher). Therefore, our protagonist must change his emotional state. Likewise, the appraisal generating the emotional activity may be mistaken (e.g., the teacher did not mean an insult, but a joke) or the expected (angry) emotional state may be in conflict with some other goal (e.g., establishing or maintaining a good relationship with the teacher).

To put the emotional system back on track, the input of the emotional system must be changed. Gaze aversion, reappraisal, and leaving the situation are possible options, all of which provide different input to the system. The cognitive and behavioral strategies to be used affect the ongoing emotional system by either replacing or modifying the input. The input can also changed through situation modification, attentional deployment (e.g., distraction and shifting attention away from the immediate situation), and cognitive change, which alter the emotional significance of the situation (cf. Gross, 1999). The change of input results in a modified course of the emotional process, which finishes a full cycle of emotion regulation. The system is back on track.

\section{Parent-Child Interaction}

Cole et al. (this issue) paid ample attention to parent-child interaction as part of the domain of emotion regulation. Our emphasis on feelings - the subjective experience of the ongoing emotional system-may seem to preclude parent-child interaction. In our view, however, the opposite is true. The ability of parents to regulate their children's emotions is at least partly based on their capacity to infer their children's feelings (i.e., the state of the emotional system).

Our three-component definition applies as follows. When the emotional state of the child diverges from what it should be (e.g., prolonged crying or unwarranted fear of a nice dog), parents may try to change the child's emotional state by changing the input to the emotional system. For example, parents may try to distract their crying infant by showing a favorite toy, an approach that might be described as attentional deployment. Or, as another example, parents with a child afraid of a nice dog may try to induce cognitive change by saying something like, “Doggy doesn't bite." The examples suggest an important analogy between emotion regulation within persons and emotion regulation between persons (here, parent and child). In both cases, regulation is required because the emotional system is getting off track. Similar strategies (cf. Gross, 1999) are used within and between persons to change the input of the emotional system as a means of changing the state of the emotional system.

\section{Methodological Consequences}

The emotional system is dynamic; that is, the state of the system changes continuously in a regular and consistent way. Feelings monitor the emotional process and play a crucial role in emotion regulations. Together, these assumptions might be used to study emotion regulation. Anger provides an example. 
Consider a person capable of regulating his or her anger. It is likely that the individual's anger will often not run its full course. If the person's feelings were sampled over a several-day period, the intensity of anger would vary little, that is, would remain relatively flat, without peak intensities. In contrast, consider a person with fewer resources to regulate his or her anger. If this individual's feelings were sampled over the course of several days, the intensity of anger would vary, with peak intensities.

These different patterns can be quantified by means of differential structural equation modeling as proposed by Boker and Nesselroade (2002), or hierarchical linear models used in Larson, Moneta, Richards, and Wilson (2002) and in Hoeksma et al. (2000). A simple measure that may be used to quantify different patterns is the standard deviation of the feeling intensities sampled over several days. The next step is to show that the different patterns can be explained by variables that are hypothesized to affect emotion regulation. These variables may range from cultural norms about the desirability and acceptability of specific emotions to fundamental neurological mechanisms and functions that are thought to affect emotion regulation. An illustration of the method is given next.

\section{Response Inhibition and Anger}

Close anatomical connections between the orbital frontal cortex and the amygdala, and results of lesions to either region, suggest that both regions are involved in emotion regulation (Kolb \& Whishaw, 2003). The prefrontal cortex and its attended networks are known to mediate executive functions (Lezak, 1995; Pennington \& Ozonoff, 1996). These mental functions enable self-control and goal-directed behavior. Response inhibition is considered a core executive function. It is the capacity to inhibit inappropriate responding and has been suggested a prerequisite for the other executive functions, including working memory and self-regulation of affect and arousal (Barkley, 1996, 1997). In particular, the orbital frontal region of the prefrontal cortex (with its reciprocal connections with the striatum) appears to mediate inhibition (Toates, 2001). Thus, response inhibition, mediated by the orbital prefrontal cortex, is a possible fundamental neurological function affecting emotion regulation.

Using the three-component definition of emotion regulation, the role of response inhibition would be explained as follows. The moment it becomes apparent that the expected state the emotional system (the current feeling) is inappropriate, response in- hibition would be needed. At that moment, the ongoing emotional system must be stopped. Stopping the system creates the time needed to change the input of the system, which in turn can change the state of the system (the next feelings). If the process is not stopped in time, the system is likely to continue its course.

These considerations lead to the hypothesis that response inhibition (in particular, the time needed to stop a response) affects the regulation of emotion (in the example, anger). We tested this hypothesis in a small observational study by studying the association between children's inhibitory control and anger variability. Participants were 30 preadolescent children (15 boys, 15 girls; White; lower to upper class; aged $10-13$ years, mean age $=11.44$ years, $S D=.61$ ) drawn equally from three elementary schools, each with one fifth- and one sixth-grade class. Following the experience-sampling method (Brandstatter, 1977; Csikszentmihalyi, Larson, \& Prescott, 1977), we collected data on the intensity of experienced anger using the Electronic Mood Device (EMD; Hoeksma et al., 2000), which provides a small portable electronic version of a 9-point mood adjective scale. The EMD signaled children to rate their anger and eight other feelings every hour with a random interval up to $5 \mathrm{~min}$. Feelings were presented in random order, with reports requested for 3 to 4 days, providing 1,083 records, averaging 38.7 anger ratings per child. We converted each series of anger ratings to its standard deviations reflecting the child's variability of anger.

The inhibitory process was measured using the Stop Signal Paradigm (SSP; Logan, 1994; Logan \& Cowan, 1984) based on the theory of inhibitory control known as the race model (for review, see Logan, 1994; Logan \& Cowan, 1984). The paradigm taps the individual's success in inhibiting different kinds of responses, including eye movements, hand movements, squeezes, and speech (Logan, 1994), measuring the latency of the time needed to stop the inappropriate response (called the stop signal reaction time [SSRT]).

To measure SSRT, children wearing headphones were seated in front of a dark computer screen with a push button located on each side. The first 64 trials were presented in which a small, stylized plane was shown pointing to either the right or left corner of the screen. Children were instructed to push as quickly as possible either the right or left button to match the direction of the plane. The next four blocks of trials consisted of 48 go trials and 16 stop trials in random order. Stop trials were identical to go trials except that an audible stop signal was presented for which 


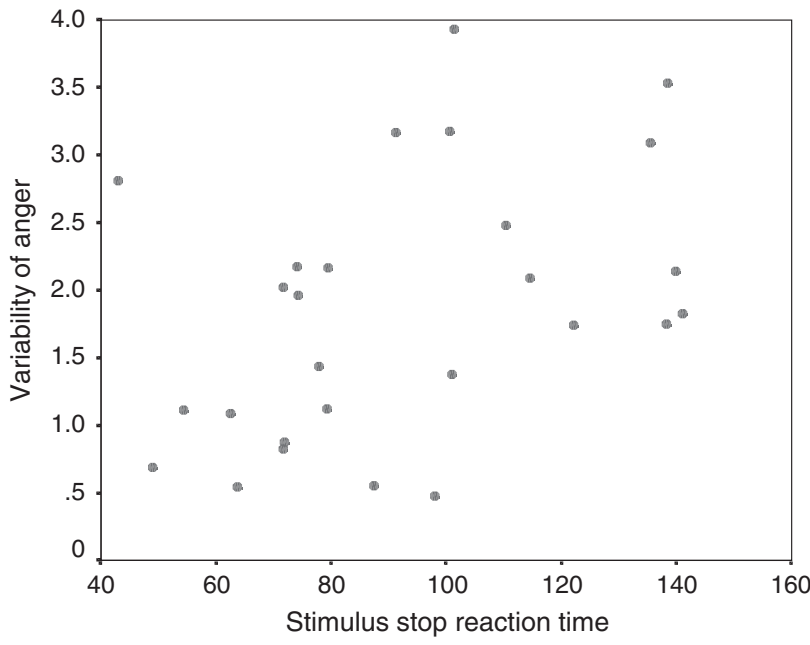

Figure 1 . The variability of anger against stimulus stop reaction time.

children were instructed not to press either of the two buttons, that is, to inhibit their response. The interval between the onset of the go stimulus and onset of the stop signal varied dynamically, contingent on the child's responses, using a tracking algorithm proposed by Osman, Kornblum, and Meyer (1986). The dynamic tracking algorithm has been shown to result in an efficient and reliable estimate of SSRT (Logan, 1994; Logan, Schachar, \& Tannock, 1997).

Data sampled with the EMD and the SSP were first checked for outliers using box and whisker plots (Chambers, Cleveland, Kleiner, \& Tukey, 1983). One outlier for the SSRT was detected and these data were deleted. The mean standard deviation of the variability of anger was $1.86(S D=.97)$. The mean time needed to inhibit the response (SSRT) was 92.3 $\mathrm{ms}(S D=29.5)$. Figure 1 shows variability of anger plotted against the SSRT. The estimated Pearson correlation was $r=.41 \quad(p<.05$, one-sided, $n=27)$, pointing to a moderate to strong relation between the SSRT and variability of anger. Given our assumption that the ability to regulate anger leads to low variability of anger, the correlation is clearly consistent with our hypothesis that response inhibition affects the regulation of anger. This analysis shows that individual differences in variability of emotion are meaningfully related to individual differences in executive functioning likely to affect emotion regulation.

\section{Conclusion}

Regulation is intrinsic to emotion (Frijda, 1986). The three-component definition of emotion regulation based on a dynamic perspective suggests, however, that the processes of emotion and emotion regulation may be clearly distinguished, both conceptually and methodologically. The dynamic perspective leads to a focus on change and variability of feelings. The observed correlation between the variability of anger and response inhibition is consistent with the hypothesized role of the orbital prefrontal cortex in emotion regulation. The major contribution of these data, however, is its support for the notion that emotions and emotion regulation can be fruitfully examined by looking at the change and variability of feelings.

In conclusion, we have presented a conceptual and methodological framework for studying emotion regulation that we suggest may be useful for answering a number of questions in emotion-regulation research. We end by posing three such questions. How do asymmetries between increasing and decreasing emotions and between positive and negative emotions affect emotion regulation? How do subtle differences in emotional awareness of feelings, ranging from unawareness (Damasio, 2000b) to structured knowledge about feelings (Davidson, 1998) affect emotion regulation? And finally, is it possible to develop statistical time-series models that allow for an analytical distinction between the ongoing emotional system, feelings, and regulation?

\section{References}

Barkley, R. A. (1996). Linkages between attention and executive functions. In G. R. Lyon \& N. A. Krasnegor (Eds.), Attention, memory, and executive function (pp. 307326). Baltimore: Brookes.

Barkley, R. A. (1997). Behavioral inhibition, sustained attention, and executive functions: Constructing a unified theory of ADHD. Psychological Bulletin, 121, 65-94.

Boker, S. M., \& Nesselroade, J. R. (2002). A method for modeling the intrinsic dynamics of intraindividual variability: Recovering the parameters of a simulated oscillator in multi-wave panel data. Multivariate Behavioral Research, 37, 127-160.

Box, G. E. P., Jenkins, G. M., \& Reinsel, G. C. (1994). Time series analysis: Forecasting and control. Englewood Cliffs, NJ: Prentice Hall.

Brandstatter, H. (1977). Wohlbefinden and Unbehagen. Entwurf eines Verfahrens zur Messing situationsabhangiger Stimmungen.[Well-being and uneasiness. The design of an instrument to meuasure situation depedent mood]. In W. H. Tack (Ed.), Bericht uber den 30. Kongress der DGPs in Regensburg 1976 (pp. 60-62). Gottingen, Germany: Hogrefe.

Cacioppo, J. T., Berntson, G. G., Larsen, J. T., Poehlmann, K. M., \& Ito, T. A. (2000). Psychophysiology of emotion. In 
M. D. Lewis \& J. M. Haviland (Eds.), Handbook of emotions (2nd ed., pp. 829-843). New York: Guilford Press.

Chambers, J. M., Cleveland, W. S., Kleiner, B., \& Tukey, P. A. (1983). Graphical methods for data analysis. Pacific Grove, CA: Wadsworth \& Brooks/Cole.

Cole, P. M., Martin, S. E., \& Dennis, T. A. (2004). Emotion regulation as a scientific construct: Methodological challenges and directions for child development research. Child Development, 75, 317-333.

Csikszentmihalyi, M., Larson, P., \& Prescott, S. (1977). The ecology of adolescent activity and experience. Journal of Youth and Adolescence, 6, 281-294.

Damasio, A. R. (1994). Decarte's error. New York: Avon.

Damasio, A. R. (2000a). The feeling of what happens: Body and emotion in the making of consciousness. New York: Harcourt Brace.

Damasio, A. R. (2000b). A second chance for emotions. In R. D. Lane \& L. Nadel (Eds.), Cognitive neuroscience of emotion (pp. 12-23). New York: Oxford University Press.

Davidson, R. J. (1998). Affective style and affective disorders: Perspectives from affective neuroscience. Cognition and Emotion, 12, 307-330.

Davidson, R. J., \& Irwin, W. (1999). The functional neuroanotomy of emotion and affective style. Trends in Cognitive Sciences, 3, 11-21.

Ekman, P. (1972). Universals and cultural differences in facial expression of emotion. In J. Cole (Ed.), Nebraska Symposium on Motivation (pp. 207-283) Lincoln: University of Nebraska Press.

Freeman, W. J. (2000). Emotion is essential to all intentional behaviors. In M. D. Lewis \& I. Granic (Eds.), Emotion, development, and self-organization: Dynamic systems approaches to emotional development (pp. 209-235) Cambridge, England: Cambridge University Press.

Frijda, N. H. (1986). The emotions. Cambridge, England: Cambridge University Press.

Frijda, N. H., \& Zeelenberg, M. (2001). Appraisal: What is the dependent? In K. R. Scherer, A. Schorr, \& T. Johnstone (Eds.), Appraisal processes in emotions (pp. 141155). Oxford, England: Oxford University Press.

Goodwin, G. C., \& Sin, K. S. (1984). Adaptive filtering prediction and control. Englewood Cliffs, NJ: Prentice Hall.

Gottman, J. M. (1981). Time series analysis: A comprehensive introduction for social scientists. Cambridge, England: Cambridge University Press.

Greenfield, S. A. (2000.). The private life of the brain. London: Penguin Press.

Grewal, S. M., \& Andrews, A. P. (1993). Kalman filtering: Theory and practice. Englewood Cliffs, NJ: Prentice Hall.

Gross, J. J. (1999). Emotion regulation: Past present and future. Cognition and Emotion, 13, 551-573.

Heilman, K. M. (2000). Emotional experience: A neurological model. In R. D. Lane \& L. Nadel (Eds.), Cognitive neuroscience of emotion (pp. 328-344). Oxford, England: Oxford University Press.

Hobson, J. A. (2001). The dream drugstore. Cambridge, MA: MIT Press.
Hoeksma, J. B., Sep, S. M., Vester, F. C., Groot, P. F. C., Sijmons, R., \& de Vries, J. (2000). The electronic mood device: Design, construction and application. Behavior Research Methods, Instruments E Computers, 32, $322-326$.

James, W. (1884). What is an emotion? Mind, 9, 188-205.

Kamen, E. W., \& Heck, B. S. (1997). Fundamentals of signals and systems using matlab. Englewood Cliffs, NJ: Prentice Hall.

Kolb, B., \& Whishaw, I. Q. (2003). Fundamentals of human neuropsychology (5th ed.), New York: Freeman.

Larson, R. W., Moneta, G., Richards, M. H., \& Wilson, S. (2002). Continuity, stability and change in daily emotional experience. Child Development, 73, 1151-1165.

Lazarus, R. S. (1991). Emotion and adaptation. New York: Oxford University Press.

Lewis, M. D. (1996). Self-organising appraisals. Cognition and Emotion, 10, 1-25.

Lezak, M. D. (1995). Neuropsychological assessment (3rd ed.), New York: Oxford University Press.

Logan, G. D. (1994). On the ability to inhibit thought and action: A users' guide to the Stop Signal Paradigm. In D. Dagenbach \& T. H. Carr (Eds.), Inhibitory processes in attention, memory, and language (pp. 189-239). San Diego, CA: Academic Press.

Logan, G. D., \& Cowan, W. B. (1984). On the ability to inhibit thought and action: A theory of an act of control. Psychological Review, 91, 295-327.

Logan, G. D., Schachar, R. J., \& Tannock, R. (1997). Impulsivity and inhibitory control. Psychological Science, 8 , 60-64.

Maquet, P., Peters, J., Aerts, J., Delfiore, G., Degueldre, C. \& Luxen, A. (1996, September 12). Functional neuroanatomy of human rapid-eye-movement sleep and dreaming. Nature, 383, 163-166.

Osman, A., Kornblum, S., \& Meyer, D. E. (1986). Controlled and ballistic stages of response preparation. Journal of Experimental Psychology: Human Perception and Performance, 12, 243-258.

Panksepp, J. (1998). Affective neuroscience: The foundations of human and animal emotions. New York: Oxford University Press.

Pennington, B. F., \& Ozonoff, S. (1996). Executive functions and developmental psychopathology. Journal of Child Psychology and Psychiatry, 37, 51-87.

Plutchik, R. (1962). The emotions: Facts, theories and a new model. New York: Random House.

Scherer, K. R. (1987). Toward a dynamic theory of emotion: The component model of affective sates. Geneva Studies in Emotion and Communication, 1, 1-96. Available from http://www.unige.ch/fapse/emotion/genstudies/gen studies.html.

Scherer, K. R. (2000). Emotions as episodes of subsystem synchronization driven by non linear appraisal processes. In M. D. Lewis \& I. Granic (Eds.), Emotion, development, and self-organization: Dynamic systems approaches to emotional development (pp. 70-99). Cambridge, England: Cambridge University Press. 
Scherer, K. R. (2001). Appraisal considered as a process of multilevel sequential checking. In K. R. Scherer, A. Schorr, \& T. Johnstone (Eds.), Appraisal processes in emotions (pp. $92-120)$. Oxford, England: Oxford University Press.

Schore, A. N. (2000). The self-organization of the right brain and the neurobiology of emotional development. In M. D. Lewis \& I. Granic (Eds.), Emotion, development, and self-organization: Dynamic systems approaches to emotional development (pp. 155-185). Cambridge, England: Cambridge University Press.

Solomon, B. (2002). President's column "Meeting in Spain". Emotion Researcher, 16, 3-4.

Toates, F. (2001). Biological psychology. Harlow, England: Pearson Education. 
This document is a scanned copy of a printed document. No warranty is given about the accuracy of the copy. Users should refer to the original published version of the material. 